TENDENCIAS

Revista de la Facultad de Ciencias

Económicas y Administrativas.

Universidad de Nariño

ISSN-E 2539-0554

Vol. XXIII No. 1 - 1er Semestre 2022

Enero - Junio - Páginas 29-57

\title{
ENVEJECIMIENTO Y LA TRANSICIÓN DE LA ESTRUCTURA POBLACIONAL POR EDADES EN COLOMBIA
}

\author{
POPULATION AGEING AND THE AGE TRANSITION IN COLOMBIA \\ ENVELHECIMENTO DA POPULAÇÃO E A TRANSIÇÃO DE IDADES NA \\ COLÔMBIA
}

Elizabeth Castellanos; Indira Vega; César Cristancho Fajardo

Magíster en Estudios de población, Universidad Externado de Colombia. Docente investigadora de la Facultad de Ciencias Sociales y Humanas. Universidad Externado de Colombia. ORCiD: 0000-0002-7652-0972. E-mail: elizabeth.castellano@uexternado.edu.co, Colombia.

Magíster (C) en Responsabilidad Social y Sostenibilidad, Universidad Externado de Colombia. Docente de la Facultad de Ciencias Sociales y Humanas. Universidad Externado de Colombia. ORCiD: 0000-0002-6074-949X. E-mail: indira.vega @uexternado.edu.co, Colombia.

Doctor en Demografía, Universidad Autónoma de Barcelona. Investigador, Universidad Nacional de Colombia e investigador, Universidad Externado de Colombia. ORCiD: 0000-0002-1900-2140. E-mail: cesar.cristancho@uexternado.edu.co,Colombia.

Recibido: 16 de octubre de 2021

Aprobado: 20 de diciembre de 2021

DOI: https://doi.org/10.22267/rtend.222301.197 


\title{
Resumen
}

El objetivo de esta investigación es analizar el perfil sociodemográfico de las personas de edades avanzadas en Colombia. La principal fuente de información está constituida por los resultados de los Censos de Población y Vivienda, con énfasis en el realizado en 2018. En el desarrollo de la investigación se analizaron niveles, tendencias y desigualdades geográficas del envejecimiento poblacional en Colombia. En los resultados, se identificó que una de las principales transformaciones de la estructura poblacional de Colombia es el proceso de feminización de las edades avanzadas, impulsado por la mayor esperanza de vida al nacer de las mujeres. Por otro lado, se encontró una clara diferenciación de los roles de género en los hogares con población de edad, en la cual la mayoría de los hombres son identificados como jefes de hogar y tienen una mayor participación laboral hasta edades avanzadas y las mujeres son sus parejas y se encargan del cuidado del hogar y sus integrantes. Así mismo, se comprobó que la participación en la actividad laboral es una opción para las personas de edad con mejores condiciones económicas y acceso a pensiones; mientras que para las que acumulan mayores desventajas económicas no constituiría una opción sino una obligación.

Palabras clave: censos de población; demografía; género; hogares; objetivos de desarrollo sostenible; personas de edad; tendencias demográficas.

JEL: J12; J14; J16; Q56; R23.

\begin{abstract}
The objective of this research is to analyze the sociodemographic profile of elderly people in Colombia. The main source of information is constituted by the results of the Population and Housing Censuses, with emphasis on the one carried out in 2018. In the development of the research, levels, trends, and geographic inequalities of population aging in Colombia were analyzed. In the results, it was identified that one of the main transformations of the Colombian population structure is the process of feminization of advanced ages, driven by the greater life expectancy at birth of women. On the other hand, a clear differentiation of gender roles was found in households with an older population, in which most men are identified as heads of household and have a higher labor participation until advanced ages and women are their couples and take care of the home and its members. Likewise, it was found that participation in work activity is an
\end{abstract}


option for older people with better economic conditions and access to pensions; while for those who accumulate greater economic disadvantages, it would not constitute an option but rather an obligation.

Keywords: population censuses; demography; gender; households; sustainable development goals; elderly; demographic trends.

JEL: J12; J14; J16; Q56; R23.

\section{Resumo}

O objetivo desta pesquisa é analisar o perfil sociodemográfico de idosos na Colômbia. A principal fonte de informação é constituída pelos resultados dos Censos Populacionais e Habitacionais, com destaque para o realizado em 2018. No desenvolvimento da pesquisa foram analisados os níveis, tendências e desigualdades geográficas do envelhecimento populacional na Colômbia. Nos resultados, identificou-se que uma das principais transformações da estrutura da população colombiana é o processo de feminização das idades avançadas, impulsionado pela maior expectativa de vida ao nascer das mulheres. Por outro lado, uma clara diferenciação de papéis de gênero foi encontrada em domicílios com uma população mais velha, em que a maioria dos homens são identificados como chefes de família e têm uma maior participação no trabalho até idades avançadas e as mulheres são seus casais e cuidam de a casa e seus membros. Da mesma forma, constatou-se que a participação na atividade laboral é uma opção para os idosos com melhores condições econômicas e acesso a pensões; enquanto para aqueles que acumulam maiores desvantagens econômicas, não constituiria uma opção, mas sim uma obrigação.

Palavras-chave: censos populacionais; demografia; gênero; famílias; metas de desenvolvimento sustentável; idoso; tendências demográficas.

JEL: J12; J14; J16; Q56; R23. 


\section{Introducción}

La transformación de la estructura poblacional por edades es catalogada como una de las principales consecuencias de la transición demográfica en Colombia. El aumento de la proporción de población en edades avanzadas tiene impactos en la organización y desarrollo de la sociedad (Pérez, 2003; Cardona y Peláez, 2012; Weeks, 2020), por lo cual es necesario formular e implementar políticas orientadas a que el aumento de la duración de vida media no repercuta en una mayor exclusión, vulneración, reproducción o amplificación de las desigualdades acumuladas en el curso de vida.

El papel de la demografía es clave no solo en la producción de información acerca de las características de la población en edades avanzadas, sino también en identificar los determinantes y consecuencias de este proceso. En relación con los primeros, se ha encontrado que el descenso de la fecundidad y la mortalidad; así como la mejora en las condiciones salud han sido los principales factores asociados al envejecimiento de la estructura poblacional (Ministerio de Salud y Protección Social, 2013; Flórez et al, 2015; Murphy, 2021). Mientras que, en relación con los segundos, Scherbov \& Sanderson (2014) señalan que estos dependen de las capacidades y productividades de las personas y de las interacciones de dichos elementos con las estructuras políticas y sociales. Por su parte, desde la perspectiva individual, Ayalon \& Tesch (2018) añaden que el envejecimiento humano puede ser visto como una construcción social, que depende los roles y representaciones sociales asignados por la cultura a las personas de edad. En este punto, conviene señalar el papel complementario de la perspectiva del envejecimiento de la persona con la del envejecimiento de la población, pues los cambios individuales y contextuales están estrechamente interrelacionados (Nieto y Palacio, 2007; Dulcey, 2010; Vejarano y Angulo, 2015).

Desde la perspectiva poblacional, en las últimas décadas, se ha dado un proceso de revolución silenciosa de la longevidad que tiene consecuencias en el aumento del número de nonagenarios y centenarios, el aumento del peso relativo de las personas en edades más avanzadas y un incremento sustancial de la edad media de la población (Fajardo y Rincón, 2000; Robine, 2011). En los países en desarrollo, como Colombia, los procesos de transición demográfica y envejecimiento poblacional se han dado de manera más acelerada que en los países pioneros en estas transformaciones (Zavala, 1996; Cotlear, 2011). En el contexto regional se ha dado énfasis a la 
medición del incremento de la cantidad absoluta de población mayor de 60 años. Sin embargo, este grupo es heterogéneo y diverso, con múltiples y particulares cursos de vida, lo que significa que los problemas y condiciones de los subgrupos poblacionales no son los mismos, al igual que sus necesidades y expectativas.

Por otra parte, la diversidad de indicadores demográficos disponibles indica que el proceso de envejecimiento poblacional no es uniforme y no existen indicios claros de convergencia en el corto plazo (Rowland, 2009). Por lo tanto, no existe un criterio único o umbral en la edad cronológica para definir el inicio de la vejez (Comisión Económica para América Latina [CEPAL], 1999); sino que más bien hay cambios en la significación de la vejez entre una generación y otra (Montes, 1994). Así mismo, cabe señalar que en la medida que se aceleran los procesos de transición demográfica y envejecimiento poblacional, se agota el denominado bono demográfico -etapa en la cual aumenta el peso relativo de la población en edades productivas- (Martínez, 2013). Esta segmentación de la vida en tres grandes grupos etarios ha sido objeto de múltiples críticas, pues puede repercutir, a nivel individual, en la discriminación por edad, ya que las personas de edad son definidos como dependientes (Angus \& Reeve 2006). No obstante, la perspectiva demográfica resulta útil para identificar patrones agregados, como el descenso de la razón de masculinidad en edades avanzadas debido al aumento desigual en la duración de vida media de hombres y mujeres y los contrastes en las estructuras poblacionales de diferentes países y sociedades (Laslett y Paillat, 1999). Luego, no se trata de que el procedimiento sea incorrecto sino más bien se trata de señalar la necesidad de elaborar interpretaciones adecuadas y bien fundamentadas.

Siguiendo con el análisis de la interrelación entre el punto de vista individual y el poblacional, es importante señalar que existe una unidad de análisis intermedia que son los hogares de los cuales hacen parte las personas. En muchos casos, resulta relevante considerar el análisis de dicha unidad pues se ha podido identificar que el envejecimiento demográfico tuvo como consecuencia la sobrevivencia simultanea de tres o más generaciones en un mismo hogar. No obstante, este fenómeno también dificultó en buena medida la cohabitación de dichas generaciones en los hogares (Redondo, 2012). 
A escala internacional existen diversos referentes y normativas que se tienen en cuenta para los análisis sobre el envejecimiento poblacional de las sociedades. En primer lugar, los Objetivos de Desarrollo Sostenible -ODS- hacen referencia explícita a las situaciones y condiciones de las personas en edades avanzadas en las metas 2.2, 11.2 y 11.7, las cuales están relacionados respectivamente con las necesidades de nutrición de las personas de edad, su acceso a sistemas de transporte seguros y sostenibles y a zonas verdes y espacios públicos. Esta visión no ha estado exenta de polémicas, pues investigadores como Courtis (2017) cuestionan que no coinciden necesariamente con las reivindicaciones más importantes de este segmento poblacional. Por otra parte, conviene destacar que a partir del Plan de Acción Internacional de Viena, en el marco de la primera asamblea mundial sobre envejecimiento en 1982, se hace énfasis en fortalecer la capacidad de los gobiernos para afrontar el envejecimiento poblacional, garantizando los derechos de las personas mayores y robusteciendo sus capacidades (Naciones Unidas, 1982).

Posteriormente, durante la Conferencia Internacional sobre la Población y el Desarrollo de Cairo de 1994, se instó a los gobiernos sobre la necesidad de garantizar las condiciones necesarias para que las personas de edad puedan llevar una vida independiente, saludable y productiva (Naciones Unidas, 1994). Por su parte, la Declaración política y Plan de Acción de Madrid de 2002 estableció la importancia de un cambio en las actitudes, políticas y prácticas para apoyar el potencial de la población que envejece, dando prioridad a los mayores en el desarrollo. (Naciones Unidas, 2003). Por último, se destaca que en 2007 la Declaración de Brasilia, reconoció los derechos de las personas de edad, a la vez que impulsó el avance hacia sociedades en las cuales sean incorporadas en las dinámicas del desarrollo (CEPAL, 2011). Esto último, sirve para destacar que se considera que existe una estrecha interrelación entre población, desarrollo socioeconómico y medio ambiente, que debe ser tenida en cuenta en la formulación e implementación de políticas públicas sobre envejecimiento poblacional.

A escala regional, un referente de gran importancia es el Consenso sobre Población y Desarrollo, realizado en Montevideo en 2013, en el cual los representantes de los países participantes, entre ellos Colombia, acordaron 15 medidas prioritarias sobre envejecimiento y protección social (CEPAL, 2013). Dentro de estas, se destacan la medida 19 orientada a formular y ejecutar políticas, planes y programas que consideren la estructura por edades, el envejecimiento 
poblacional y las oportunidades y desafíos asociados a su evolución y la medida 26 que se refiere a la adecuación de políticas en salud a los desafíos del envejecimiento poblacional y la necesidad de que el desarrollo sea inclusivo con las personas de edad, empoderándolos para el pleno respeto de sus derechos. Finalmente, se destaca que referente importante sobre el tema fue la Convención Interamericana sobre la Protección de los Derechos Humanos de las Personas Mayores (Organización de los Estados Americanos [OEA], 2015).

Teniendo en cuenta el marco de referencia planteado, el principal objetivo de esta investigación es analizar el perfil sociodemográfico de los adultos mayores, por sexo y grupos decenales de edad, en Colombia y sus departamentos según el censo 2018, e identificar los diferenciales interdepartamentales entre esos mismos tramos de edad, según el contexto socioeconómico de las unidades territoriales.

\section{Metodología}

La principal fuente de información está constituida por los resultados de los Censos de Población y Vivienda en Colombia. En este sentido, los microdatos y reportes censales de las estructuras de población por edades y sexo son insumos fundamentales para la construcción y análisis de algunos de los indicadores más utilizados desde la demografía y la discusión sobre la necesidad de formular políticas diferenciales para segmentos poblacionales específicos. Por otro lado, los censos posibilitan la estimación de indicadores robustos, con un alto nivel de desagregación geográfica y temática, para las variables incluidas en sus cuestionarios. Por tanto, el estudio corresponde a un análisis desde una perspectiva demográfica de niveles, tendencias y desigualdades geográficas del envejecimiento poblacional en Colombia. En los resultados se aborda, por una parte, la evolución de las series históricas relacionadas con la estructura poblacional por grupos de edades y sexo; y por otra parte, se desarrolla un análisis de las desigualdades geográficas en el proceso de envejecimiento poblacional de Colombia en 2018, por tratarse de la información más reciente que da cuenta de las situaciones y condiciones de las personas de edad.

Para la reconstrucción de las series históricas se tomaron los reportes oficiales de los censos de 1912 a 1985 de la biblioteca virtual del Departamento Administrativo Nacional de Estadística [DANE] y se digitalizaron apoyándose en el uso de software de reconocimiento óptico para la 
conformación de una base de datos unificada y su posterior validación. Por su parte, los censos de 1993, 2005 y 2018 se trabajaron de manera paralela mediante el sistema REDATAM que administra la CEPAL y procesamiento directo de la información disponible en el sitio web del DANE por medio de código en lenguaje $\mathrm{R}$.

Por otra parte, se analizó la variable edad según tres niveles de agrupación: grandes grupos de edades, grupos decenales y edades simples. Así mismo, se analizaron los diferenciales de los indicadores seleccionados según sexo, área geográfica, departamento de residencia y estado conyugal. Estas variables permiten analizar diferentes dimensiones del envejecimiento poblacional en Colombia desde la perspectiva temporal y espacial.

De forma complementaria, se analizaron indicadores agregados como el índice de envejecimiento, la edad mediana y el índice de masculinidad para comparar diferencias entre subpoblaciones. A continuación, se relacionan las ecuaciones utilizadas para el cálculo de estos indicadores:

$$
\begin{aligned}
& \text { Indice de envejecimiento }=\frac{N u ́ \text { mero de personas de } 60 \text { años o más }}{\text { Número de personas menores de } 15 \text { años }} \\
& \qquad \text { Edad mediana }=\frac{\left(L_{i}+\left(\frac{N}{2}\right)-F_{i}-1\right) * C}{\text { fim }}(2) \\
& \text { Indice de masculinidad }=\frac{\text { Número de hombres }}{\text { Número de mujeres }} * 100
\end{aligned}
$$

Donde en la ecuación de la edad mediana se utilizan las siguientes convenciones: P es la población; C es el tamaño del intervalo de clase; Li es el límite inferior de la clase mediana; F es la frecuencia acumulada; Fi-1 es la frecuencia acumulada anterior a la clase mediana y fim es la frecuencia de la clase mediana. 


\section{Resultados}

\section{Evolución histórica del envejecimiento poblacional según datos de los censos de población en Colombia.}

A partir de la información recopilada en los censos se puede caracterizar la transición de la estructura por edades de la población colombiana. La Figura 1 muestra que entre 1912 y 2018, se pasó de una población joven donde más del 40 por ciento correspondía al segmento etario entre 0 y 14 años a una población en proceso de envejecimiento, en la cual dicho indicador ya es inferior al 25 por ciento. Además, el peso relativo de la población de 65 años y más se incrementó de 2.6 a 9.1 por ciento durante el mismo periodo. Al igual que en otros países, estos cambios se han dado de manera gradual y reflejan las consecuencias de las variaciones en los componentes demográficos de la fecundidad, mortalidad y migraciones. Por otra parte, se puede identificar que el censo de 1964 se constituyó en un punto de inflexión de la serie de estadísticas censales; a partir de ese año se presentó un descenso sostenido del peso relativo de la población entre 0 y 14 años, a la par que se experimentó un aumento en la participación de edades intermedias y avanzadas en la población total. 


\section{Figura 1}

Colombia. Evolución de la distribución poblacional en tres grandes grupos de edades. 1912 a 2018.

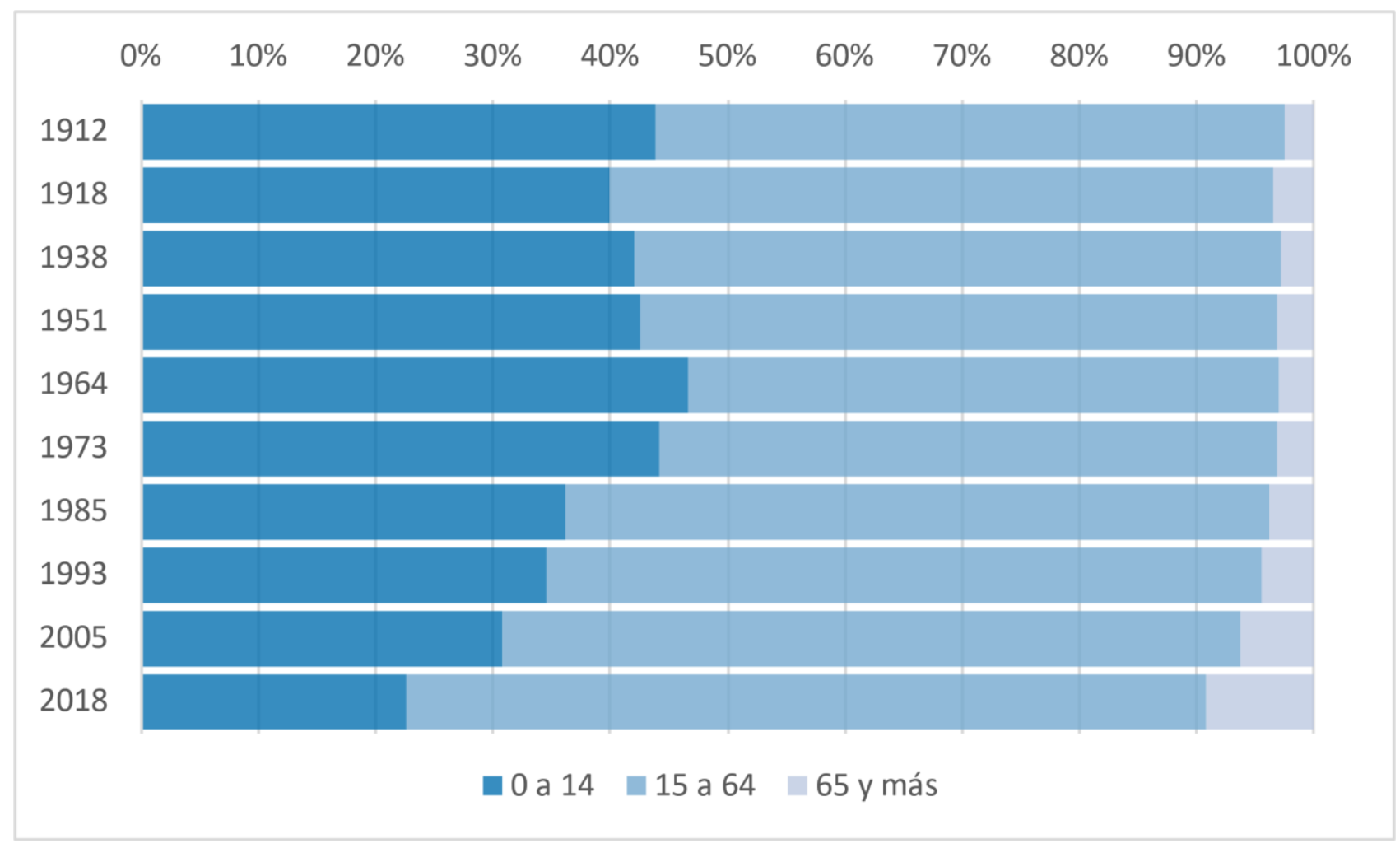

Fuente: reportes de los censos de población 1912 a 2018.

El cambio poblacional según sexo aporta un análisis complementario sobre el proceso de envejecimiento poblacional en Colombia. En la Tabla 1 se presenta la evolución de los indicadores absolutos y relativos de la población de 65 años y más, entre 1918 y 2018. Un primer aspecto que se destaca es la disminución del indicador de masculinidad en la población de 65 años y más entre 1985 y 2018, lo cual también puede analizarse como un proceso de feminización de las edades avanzadas, que sin duda ha sido impulsado por la mayor esperanza de vida de las mujeres. Lo que plantea retos importantes en materia de género, para garantizar el pleno desarrollo de las mujeres a lo largo de la vida. En relación con lo anterior, la Observación General No. 27 sobre las mujeres de edad y la protección de sus derechos, elaborada por oficina del Alto Comisionado de las Naciones Unidas para los Refugiados [ACNUR], manifiesta la preocupación por las múltiples formas de discriminación que sufren las mujeres de edad, acompañado esto de sus bajas posibilidades de acceso a seguridad económica en la vejez (ACNUR, 2010). 
Así mismo, se puede observar que el aumento, entre 1918 y 2018, en el peso relativo de este segmento etario en el caso de las mujeres excede los seis puntos porcentuales, un umbral que no se supera en el caso de los hombres. En referencia a las cantidades absolutas, el incremento también es acentuado; el número de hombres de 65 años y más paso de menos de 100 mil a más de un millón y medio durante el periodo analizado, mientras que en el caso de las mujeres el volumen poblacional de este grupo de edad aumento de un poco más de cien mil a más de dos millones de personas.

\section{Tabla 1}

Colombia. Número y proporción de personas de 65 años y más según sexo. 1918 a 2018

\begin{tabular}{|c|c|c|c|c|c|}
\hline \multirow[b]{2}{*}{ Año } & \multicolumn{2}{|c|}{ Hombres de 65 años y más } & \multicolumn{2}{|c|}{ Mujeres de 65 años y más } & \multirow{2}{*}{$\begin{array}{c}\text { Relación de } \\
\text { masculinidad } \\
\text { del grupo de } \\
\text { edades }\end{array}$} \\
\hline & Total & $\begin{array}{c}\text { Proporción } \\
\text { sobre el total } \\
\text { de hombres }\end{array}$ & Total & $\begin{array}{l}\text { Proporción } \\
\text { sobre el total } \\
\text { de mujeres }\end{array}$ & \\
\hline 1918 & 86.145 & 3,29 & 100.657 & 3,59 & 0,86 \\
\hline 1938 & 112.814 & 2,62 & 136.371 & 3,11 & 0,83 \\
\hline 1951 & 159.932 & 2,87 & 191.406 & 3,39 & 0,84 \\
\hline 1964 & 240.393 & 2,79 & 283.868 & 3,20 & 0,85 \\
\hline 1973 & 303.285 & 3,00 & 346.884 & 3,29 & 0,87 \\
\hline 1985 & 507.779 & 3,69 & 548.508 & 3,91 & 0,93 \\
\hline 1993 & 707.561 & 4,34 & 788.847 & 4,69 & 0,90 \\
\hline 2005 & 1.187 .169 & 5,84 & 1.430 .041 & 6,77 & 0,83 \\
\hline 2018 & 1.796 .214 & 8,33 & 2.240 .116 & 9,91 & 0,80 \\
\hline
\end{tabular}

Fuente: reportes de los censos de población 1912 a 2018.

El envejecimiento poblacional presenta marcadas diferencias territoriales. En la Tabla 2 se muestran el número y proporción de personas de 65 años y más según su área geográfica de residencia. Este fenómeno muestra un mayor avance en las cabeceras pero su diferencial con respecto a zonas rurales no es tan amplio como podría suponerse inicialmente. Se puede concluir que el proceso de transición urbana determinó una evolución desigual del volumen poblacional de 
este segmento etario y a su vez fue influenciado por la evolución de los componentes demográficos del cambio poblacional: mortalidad, natalidad y migración. Mientras que en 1951 el número de personas en edades avanzadas era inferior en cabeceras que en el resto de los municipios, posteriormente la situación se modificó diametralmente. A partir de 1964 se censaron más personas en áreas de cabeceras y en el censo de 2018 la población de este grupo de edades que residía en las cabeceras era más del triple de la que residía en centros poblados y áreas rurales.

Las estructuras poblacionales por edades simples y sexo permiten identificar con detalle el proceso gradual de envejecimiento poblacional en Colombia. Es notoria la disminución de la base de la pirámide poblacional, a la par que se observa un mayor porcentaje de población en edades intermedias y avanzadas. Así mismo, la Figura 2 permite verificar que la declaración de la edad en los censos de población mejoró de manera ostensible entre 1938 y 2018 a juzgar por el perfil menos irregular que presentan los censos más recientes. En este sentido, se destaca que la reconstrucción de las series históricas fue fundamental para una mejor identificación de patrones y tendencias de la transición de la estructura por edades. 
Tabla 2

Colombia. Número y proporción de personas de 65 años y más según área de residencia. 1918 a 2018

\begin{tabular}{|c|c|c|c|c|c|}
\hline \multirow[b]{2}{*}{ Año } & \multicolumn{2}{|c|}{$\begin{array}{c}\text { Población de } 65 \text { años y más } \\
\text { en cabeceras }\end{array}$} & \multicolumn{2}{|c|}{$\begin{array}{c}\text { Población de } 65 \text { años y más } \\
\text { en resto }\end{array}$} & \multirow{2}{*}{$\begin{array}{c}\text { Porcentaje } \\
\text { de población } \\
\text { de } 65 \text { años y } \\
\text { más que } \\
\text { reside en } \\
\text { cabeceras }\end{array}$} \\
\hline & Total & $\begin{array}{l}\text { Porcentaje } \\
\text { sobre el total } \\
\text { de población } \\
\text { en cabeceras }\end{array}$ & Total & $\begin{array}{c}\text { Porcentaje } \\
\text { sobre el total } \\
\text { de población } \\
\text { en resto }\end{array}$ & \\
\hline 1951 & 152.748 & 3,44 & 195.890 & 2,89 & 43,81 \\
\hline 1964 & 277.902 & 3,06 & 246.360 & 2,94 & 53,01 \\
\hline 1973 & 405.158 & 3,21 & 245.011 & 3,04 & 62,32 \\
\hline 1985 & 729.137 & 3,90 & 361.512 & 3,96 & 66,85 \\
\hline 1993 & 1.064 .133 & 4,53 & 432.274 & 4,48 & 71,11 \\
\hline 2005 & 1.956 .593 & 6,21 & 660.617 & 6,63 & 74,76 \\
\hline 2018 & 3.136 .593 & 9,20 & 899.737 & 8,95 & 77,71 \\
\hline
\end{tabular}

Fuente: reportes de los censos de población 1912 a 2018.

\section{Figura 2}

Colombia. Estructuras poblacionales por edad y sexo. 1938 a 2018
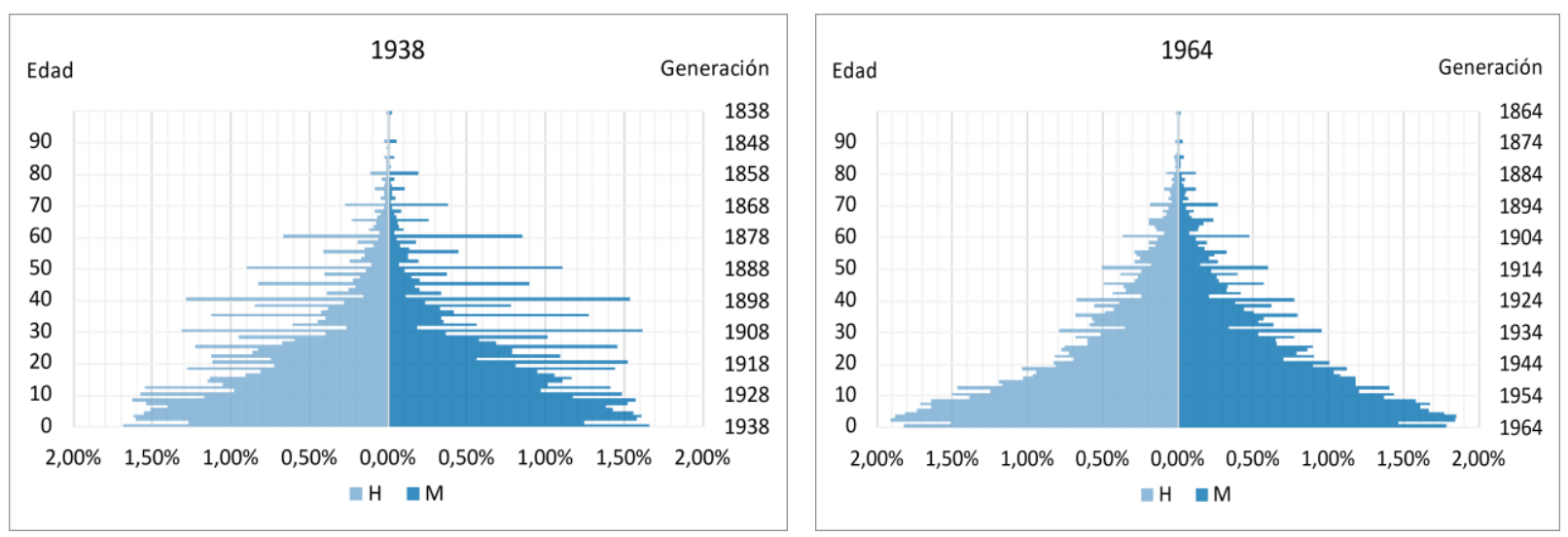

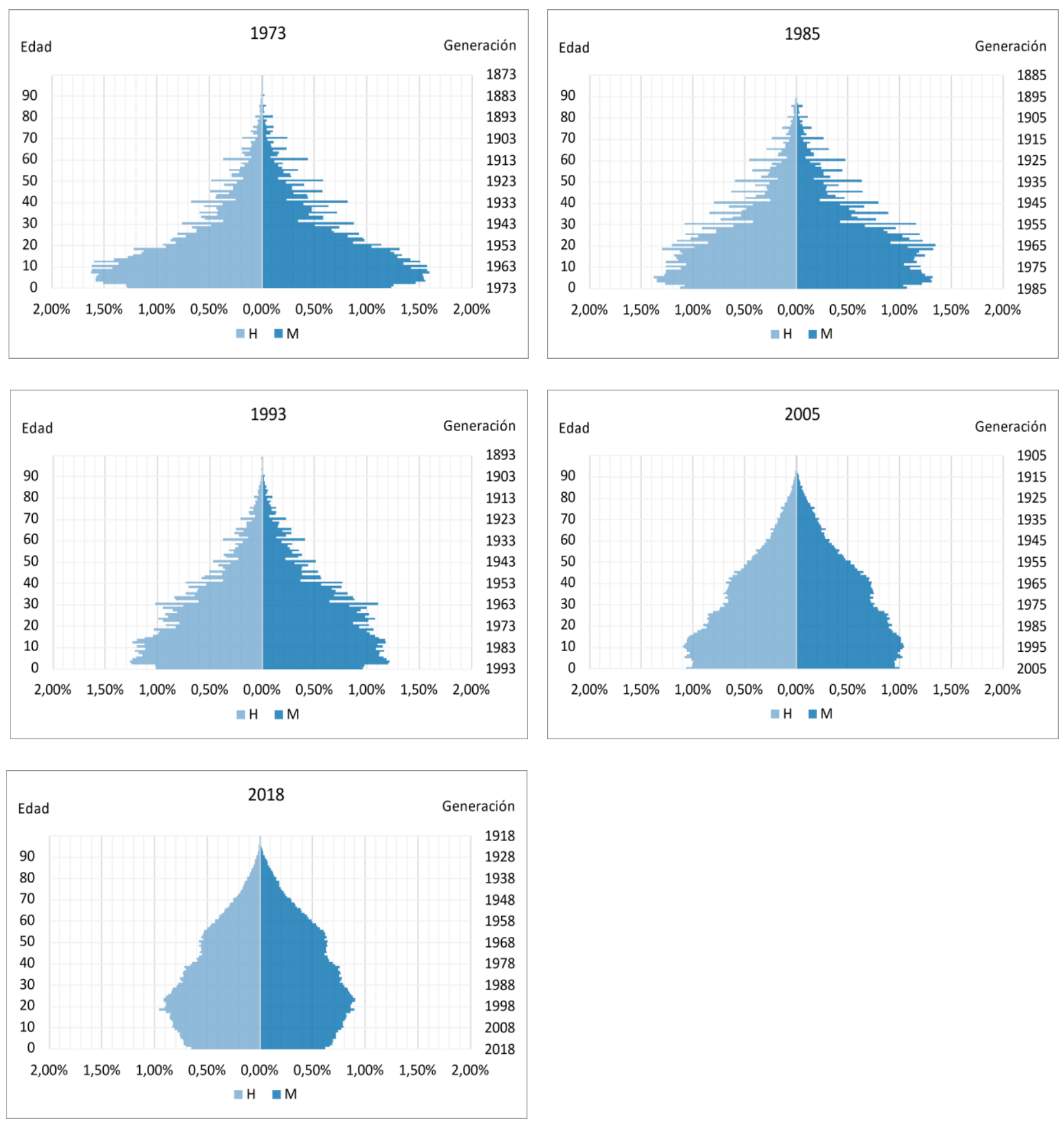

Fuente: reportes de los censos de población 1912 a 2018.

\section{Análisis de las desigualdades territoriales según los datos del Censo 2018.}

En esta sección se analizan los siguientes indicadores de estructura demográfica de los departamentos colombianos según el censo 2018: índice de envejecimiento, edad media de la población e índice de masculinidad. En cuanto al primer indicador referenciado -el índice de 
envejecimiento-, se estima que en 2018 alcanzaba un valor superior al 58 por ciento a nivel nacional. Lo cual evidencia un aumento respecto a lo estimado en censos anteriores que refleja el avance de la transición demográfica en el país. Dicho proceso transicional se relaciona con el descenso histórico de la fecundidad y la mortalidad, la reducción del volumen poblacional en edades tempranas y el inicio y evolución del bono demográfico.

Ahora bien, el nivel de avance de la transición demográfica a escala nacional enmascara la existencia de marcadas diferencias entre los departamentos (Figura 3). En consecuencia, se considera necesario comparar los indicadores departamentales con el nacional para identificar las entidades territoriales más o menos envejecidas. A través de dicho proceso se identificó que la tercera parte de los departamentos de Colombia muestran un nivel de envejecimiento superior al del total nacional. Conviene señalar que precisamente dichos departamentos tienen los mayores volúmenes poblacionales, por tanto sus cambios influyen de manera más que proporcional en la evolución de la estructura demográfica del país.

\section{Figura 3}

Indicadores de estructura demográfica en los departamentos de Colombia. Índice de envejecimiento
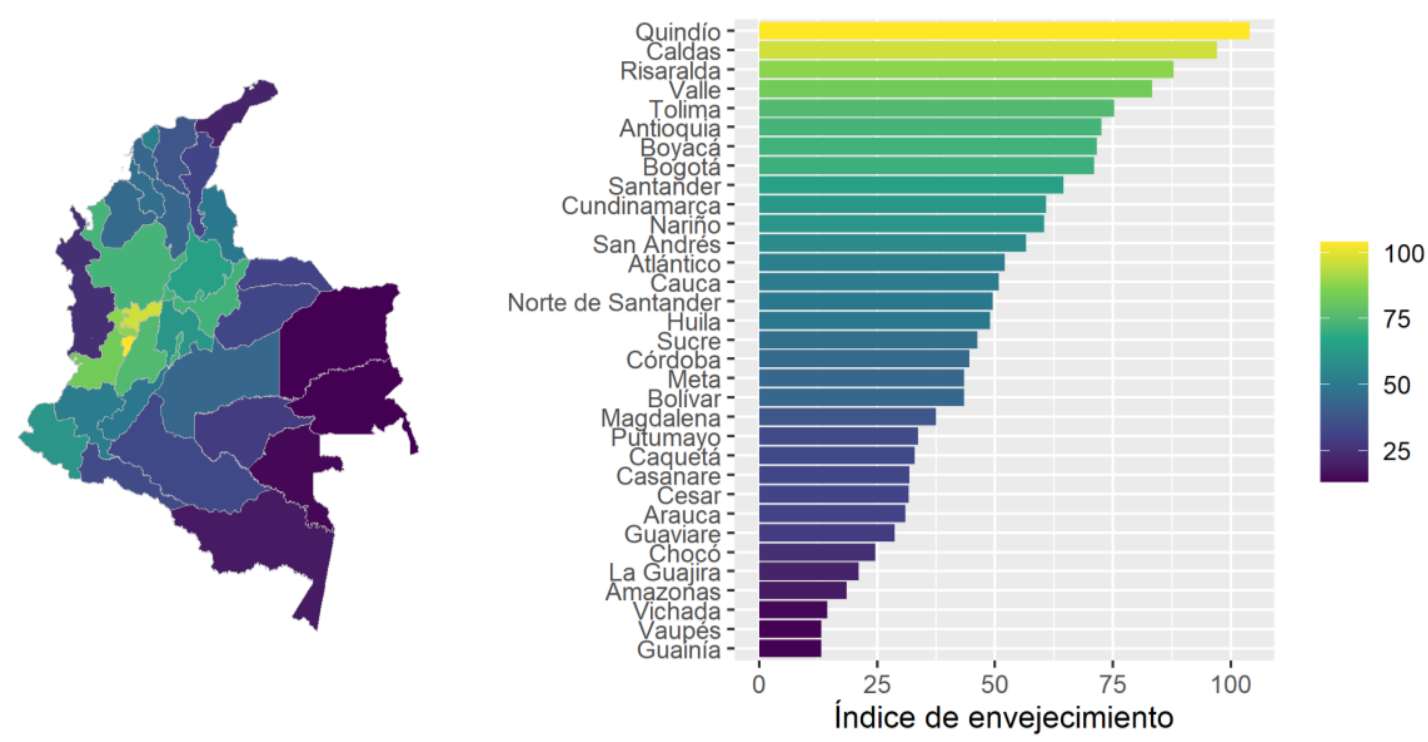


\section{Edad mediana}
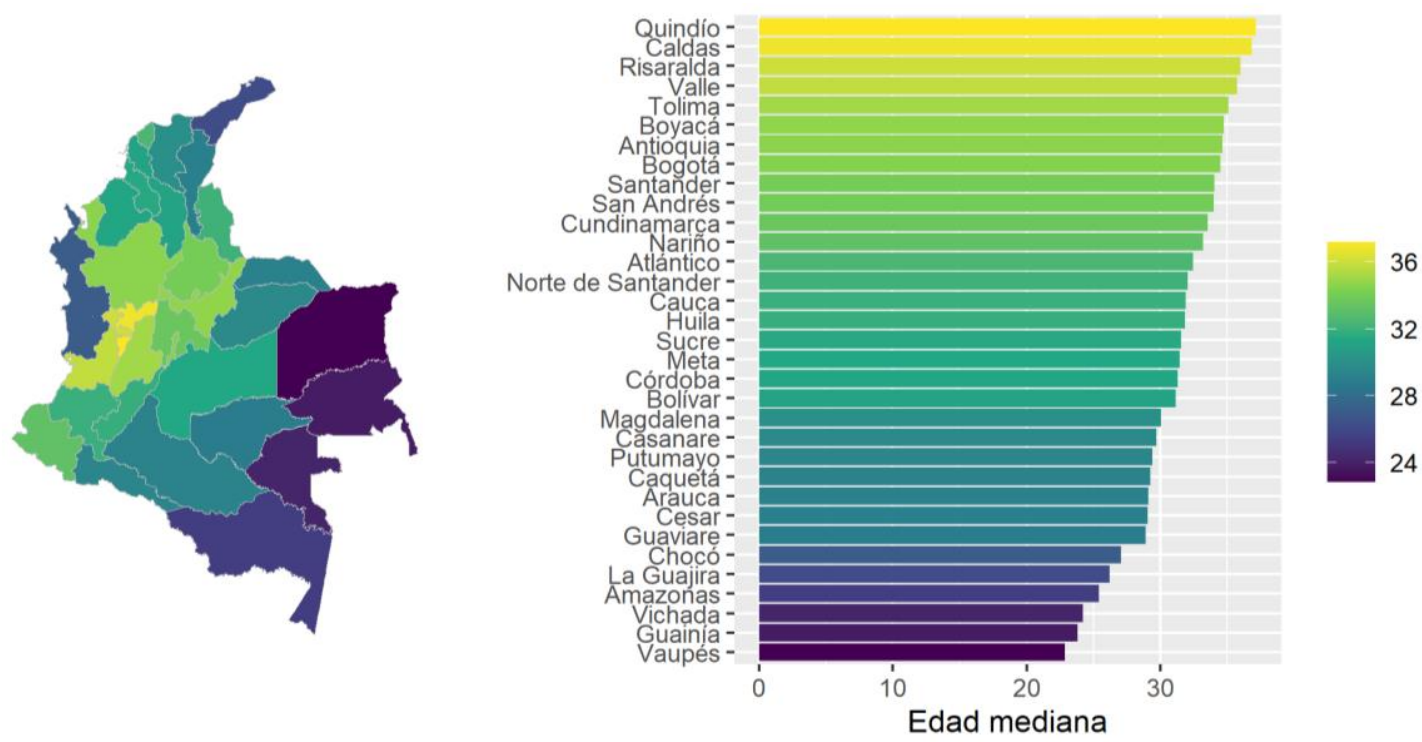

Índice de masculinidad por 100
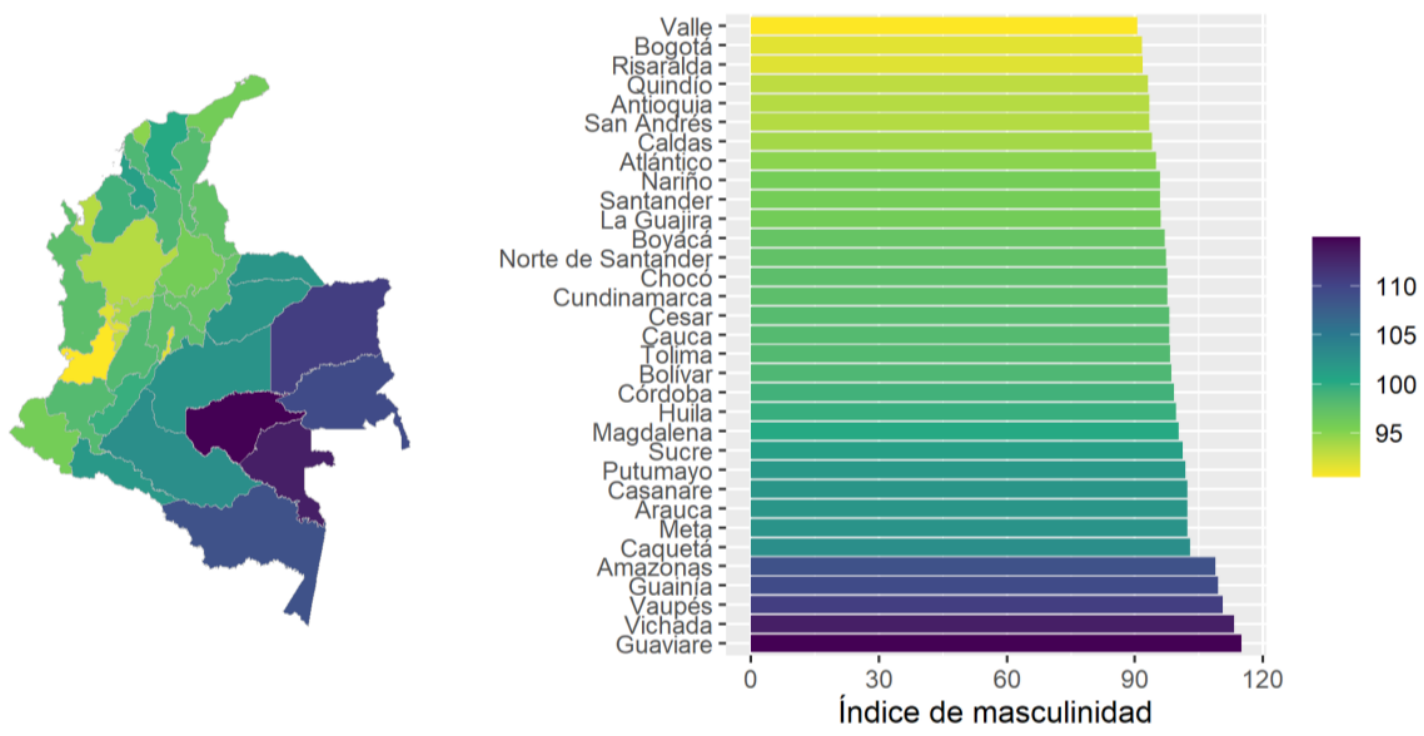

Fuente: Elaboración propia con base en el Censo 2018.

Por otra parte, el aumento sostenido de la edad media de los individuos refleja el avance del proceso de envejecimiento de la población colombiana. Por tal razón, este indicador es muy relevante para profundizar en el análisis de dicho proceso y en este sentido aporta un panorama complementario al aportado por el índice de envejecimiento. Se estima que en 2018, la población de Colombia tenía una edad media de 33 años, lo cual refleja que el país se encontraba en plena 
transición de su estructura poblacional por edades. Se puede afirmar que no se trata de una sociedad envejecida pero si de una que se encuentra en un proceso acelerado de envejecimiento poblacional.

Finalmente, en referencia al tercer indicador contrastado en este apartado -el índice de masculinidad-, se puede observar que en 2018 a nivel nacional había 95 hombres por cada 100 mujeres, mientras que en los departamentos más envejecidos los indicadores eran inferiores a dicha cota, sin duda debido a los mayores niveles de sobrevivencia hasta edades avanzadas en las mujeres. Por otro lado, se pudo identificar que 25 de 33 departamentos tenían mayores índices de masculinidad que el país en su conjunto; donde se destaca el caso de los antiguos territorios nacionales, los departamentos de creación más reciente, en los cuales el volumen de población masculina superaba a la femenina, un patrón que está estrechamente relacionado con los patrones y las tendencias de migración interna en Colombia.

Los análisis subsiguientes se enfocan únicamente en los departamentos más envejecidos. Se realiza una caracterización de la población de 60 años y más de acuerdo con un conjunto de variables del Censo 2018 que se consideraron de interés para los objetivos de esta investigación. Los departamentos seleccionados para los análisis son: Antioquia, Boyacá, Caldas, Quindío, Risaralda, Tolima y Valle.

El primer perfil que se estudia es el referente al estado conyugal de los adultos mayores (Tabla 3). Se puede observar que la mayor parte de la población en edades avanzadas estaba unida, ya sea casados o en unión libre. Mientras que en segundo lugar en cuanto a frecuencia se situaba la población viuda. Así mismo, se identificó que los niveles más altos de viudez se presentaban entre 70 y 79 años, lo cual es consistente con las altas tasas de mortalidad de este grupo etario. Por otra parte, llama la atención que la proporción de adultos mayores solteros supere a la de divorciados o separados. Probablemente la explicación de este patrón se debe a que los informantes consideran que al finalizar una unión no se entra a formar parte de los divorciados o separados, sino que nuevamente se pasa a un estado de soltería.

Posteriormente, se analizaron los resultados referentes a la posición que tenían las personas de edades avanzadas con respecto al jefe del hogar (Tabla 4). Se observa que más de la mitad de los 
adultos mayores en los departamentos envejecidos corresponden a jefes o jefas de hogar. Así mismo, se destaca que el indicador de jefatura disminuye a medida que aumenta la edad, lo cual puede estar relacionado con múltiples transiciones que ocurren en esta etapa del ciclo vital. Por un lado, aumenta la probabilidad de morir a través de las edades; por otro lado, al aumentar los niveles de viudez puede haber un incremento en las reagrupaciones familiares con los hijos, más si se tiene en cuenta que a mayor edad también aumenta los niveles de dependencia para la realización de actividades cotidianas. 
Tabla 3

Estado conyugal de la población de 60 y más años en los departamentos más envejecidos de Colombia.

\begin{tabular}{|c|c|c|c|c|c|c|c|}
\hline Categoría & Antioquia & Boyacá & Caldas & Quindío & Risaralda & Tolima & Valle \\
\hline UNID & $51,4 \%$ & $56,3 \%$ & $51,9 \%$ & $49,2 \%$ & $50,3 \%$ & $53,0 \%$ & $50,3 \%$ \\
\hline 60 a 69 & $31,7 \%$ & $33,3 \%$ & $31,9 \%$ & $29,8 \%$ & $30,9 \%$ & $31,8 \%$ & $30,4 \%$ \\
\hline 70 a 79 & $14,5 \%$ & $16,8 \%$ & $14,8 \%$ & $14,3 \%$ & $14,5 \%$ & $15,7 \%$ & $14,5 \%$ \\
\hline 80 a 89 & $4,6 \%$ & $5,6 \%$ & $4,7 \%$ & $4,5 \%$ & $4,4 \%$ & $4,9 \%$ & $4,8 \%$ \\
\hline 90 a 99 & $0,6 \%$ & $0,5 \%$ & $0,5 \%$ & $0,5 \%$ & $0,5 \%$ & $0,6 \%$ & $0,6 \%$ \\
\hline 100 y más & $0,1 \%$ & $0,1 \%$ & $0,0 \%$ & $0,1 \%$ & $0,1 \%$ & $0,0 \%$ & $0,1 \%$ \\
\hline DIV/SEP & $10,0 \%$ & $7,6 \%$ & $10,2 \%$ & $11,9 \%$ & $11,3 \%$ & $10,2 \%$ & $11,6 \%$ \\
\hline 60 a 69 & $6,7 \%$ & $4,9 \%$ & $6,8 \%$ & $7,7 \%$ & $7,4 \%$ & $6,3 \%$ & $7,2 \%$ \\
\hline 70 a 79 & $2,6 \%$ & $2,0 \%$ & $2,7 \%$ & $3,3 \%$ & $3,1 \%$ & $2,9 \%$ & $3,3 \%$ \\
\hline 80 a 89 & $0,6 \%$ & $0,6 \%$ & $0,7 \%$ & $0,9 \%$ & $0,8 \%$ & $0,8 \%$ & $1,0 \%$ \\
\hline 90 a 99 & $0,1 \%$ & $0,1 \%$ & $0,1 \%$ & $0,1 \%$ & $0,1 \%$ & $0,1 \%$ & $0,1 \%$ \\
\hline 100 y más & $0,0 \%$ & $0,0 \%$ & $0,0 \%$ & $0,0 \%$ & $0,0 \%$ & $0,0 \%$ & $0,0 \%$ \\
\hline VIUD & $20,8 \%$ & $22,4 \%$ & $21,4 \%$ & $21,0 \%$ & $21,7 \%$ & $20,8 \%$ & $20,8 \%$ \\
\hline 60 a 69 & $6,5 \%$ & $6,1 \%$ & $6,4 \%$ & $6,2 \%$ & $6,7 \%$ & $5,7 \%$ & $5,8 \%$ \\
\hline 70 a 79 & $7,2 \%$ & $8,1 \%$ & $7,6 \%$ & $7,5 \%$ & $7,9 \%$ & $7,6 \%$ & $7,4 \%$ \\
\hline 80 a 89 & $5,5 \%$ & $6,7 \%$ & $5,9 \%$ & $5,9 \%$ & $5,7 \%$ & $6,1 \%$ & $6,0 \%$ \\
\hline 90 a 99 & $1,5 \%$ & $1,4 \%$ & $1,4 \%$ & $1,4 \%$ & $1,4 \%$ & $1,4 \%$ & $1,5 \%$ \\
\hline 100 y más & $0,1 \%$ & $0,1 \%$ & $0,1 \%$ & $0,1 \%$ & $0,1 \%$ & $0,1 \%$ & $0,1 \%$ \\
\hline SOLT & $17,8 \%$ & $13,7 \%$ & $16,5 \%$ & $18,0 \%$ & $16,6 \%$ & $16,0 \%$ & $17,3 \%$ \\
\hline 60 a 69 & $10,8 \%$ & $7,5 \%$ & $9,6 \%$ & $10,6 \%$ & $9,8 \%$ & $8,9 \%$ & $10,0 \%$ \\
\hline 70 a 79 & $4,7 \%$ & $4,0 \%$ & $4,8 \%$ & $5,1 \%$ & $4,8 \%$ & $4,8 \%$ & $4,9 \%$ \\
\hline 80 a 89 & $1,8 \%$ & $1,8 \%$ & $1,9 \%$ & $1,9 \%$ & $1,7 \%$ & $2,0 \%$ & $2,0 \%$ \\
\hline 90 a 99 & $0,4 \%$ & $0,3 \%$ & $0,3 \%$ & $0,3 \%$ & $0,3 \%$ & $0,3 \%$ & $0,4 \%$ \\
\hline 100 y más & $0,1 \%$ & $0,0 \%$ & $0,0 \%$ & $0,0 \%$ & $0,1 \%$ & $0,0 \%$ & $0,0 \%$ \\
\hline
\end{tabular}

Fuente: Elaboración propia con base en el Censo 2018. Nota: UNID corresponde a unión libre o casado; DIV/SEP es divorciado o separado; VIUD es viudo o viuda; SOLT es soltero o soltera. 


\section{Tabla 4}

Parentesco con el jefe del hogar de la población de 60 y más años en los departamentos más envejecidos.

\begin{tabular}{|c|c|c|c|c|c|c|c|}
\hline Categoría & Antioquia & Boyacá & Caldas & Quindío & Risaralda & Tolima & Valle \\
\hline JHOG & $60,00 \%$ & $64,25 \%$ & $56,23 \%$ & $59,84 \%$ & $58,49 \%$ & $62,69 \%$ & $59,65 \%$ \\
\hline 60 a 69 & $33,40 \%$ & $33,01 \%$ & $30,46 \%$ & $32,58 \%$ & $32,40 \%$ & $33,00 \%$ & $31,93 \%$ \\
\hline 70 a 79 & $18,07 \%$ & $20,74 \%$ & $17,47 \%$ & $18,82 \%$ & $18,25 \%$ & $20,28 \%$ & $18,67 \%$ \\
\hline 80 a 89 & $7,27 \%$ & $9,29 \%$ & $7,20 \%$ & $7,39 \%$ & $6,83 \%$ & $8,26 \%$ & $7,82 \%$ \\
\hline 90 a 99 & $1,18 \%$ & $1,14 \%$ & $1,05 \%$ & $0,98 \%$ & $0,93 \%$ & $1,09 \%$ & $1,15 \%$ \\
\hline 100 y más & $0,08 \%$ & $0,08 \%$ & $0,05 \%$ & $0,06 \%$ & $0,08 \%$ & $0,06 \%$ & $0,08 \%$ \\
\hline PJEF & $20,22 \%$ & $22,53 \%$ & $18,78 \%$ & $19,01 \%$ & $19,07 \%$ & $20,12 \%$ & $19,37 \%$ \\
\hline 60 a 69 & $13,24 \%$ & $14,20 \%$ & $12,50 \%$ & $12,59 \%$ & $12,67 \%$ & $12,99 \%$ & $12,60 \%$ \\
\hline 70 a 79 & $5,38 \%$ & $6,44 \%$ & $4,97 \%$ & $5,07 \%$ & $5,08 \%$ & $5,59 \%$ & $5,21 \%$ \\
\hline 80 a 89 & $1,42 \%$ & $1,74 \%$ & $1,19 \%$ & $1,24 \%$ & $1,19 \%$ & $1,40 \%$ & $1,40 \%$ \\
\hline 90 a 99 & $0,15 \%$ & $0,13 \%$ & $0,10 \%$ & $0,10 \%$ & $0,10 \%$ & $0,12 \%$ & $0,14 \%$ \\
\hline 100 y más & $0,03 \%$ & $0,02 \%$ & $0,01 \%$ & $0,01 \%$ & $0,03 \%$ & $0,01 \%$ & $0,02 \%$ \\
\hline HIJ & $1,53 \%$ & $0,92 \%$ & $1,47 \%$ & $1,47 \%$ & $1,49 \%$ & $1,14 \%$ & $1,53 \%$ \\
\hline 60 a 69 & $1,41 \%$ & $0,86 \%$ & $1,36 \%$ & $1,35 \%$ & $1,36 \%$ & $1,06 \%$ & $1,39 \%$ \\
\hline 70 a 79 & $0,11 \%$ & $0,06 \%$ & $0,11 \%$ & $0,11 \%$ & $0,12 \%$ & $0,07 \%$ & $0,13 \%$ \\
\hline 80 a 89 & $0,01 \%$ & $0,00 \%$ & $0,01 \%$ & $0,01 \%$ & $0,01 \%$ & $0,00 \%$ & $0,01 \%$ \\
\hline 90 a 99 & $0,00 \%$ & $0,00 \%$ & $0,00 \%$ & $0,00 \%$ & $0,00 \%$ & $0,00 \%$ & $0,00 \%$ \\
\hline 100 y más & $0,00 \%$ & $0,00 \%$ & $0,00 \%$ & $0,00 \%$ & $0,00 \%$ & $0,00 \%$ & $0,00 \%$ \\
\hline YER/NUE & $0,25 \%$ & $0,17 \%$ & $6,70 \%$ & $0,34 \%$ & $0,33 \%$ & $0,24 \%$ & $0,35 \%$ \\
\hline 60 a 69 & $0,14 \%$ & $0,09 \%$ & $2,15 \%$ & $0,21 \%$ & $0,18 \%$ & $0,14 \%$ & $0,20 \%$ \\
\hline 70 a 79 & $0,06 \%$ & $0,05 \%$ & $2,12 \%$ & $0,07 \%$ & $0,09 \%$ & $0,06 \%$ & $0,09 \%$ \\
\hline 80 a 89 & $0,04 \%$ & $0,02 \%$ & $1,89 \%$ & $0,05 \%$ & $0,05 \%$ & $0,04 \%$ & $0,05 \%$ \\
\hline 90 a 99 & $0,01 \%$ & $0,01 \%$ & $0,52 \%$ & $0,01 \%$ & $0,01 \%$ & $0,01 \%$ & $0,01 \%$ \\
\hline 100 y más & $0,00 \%$ & $0,00 \%$ & $0,02 \%$ & $0,00 \%$ & $0,00 \%$ & $0,00 \%$ & $0,00 \%$ \\
\hline PAD/MAD & $7,84 \%$ & $6,02 \%$ & $6,57 \%$ & $8,09 \%$ & $8,88 \%$ & $7,37 \%$ & $8,39 \%$ \\
\hline 60 a 69 & $2,61 \%$ & $1,51 \%$ & $2,05 \%$ & $2,59 \%$ & $2,89 \%$ & $2,03 \%$ & $2,60 \%$ \\
\hline 70 a 79 & $2,43 \%$ & $1,85 \%$ & $2,10 \%$ & $2,58 \%$ & $2,88 \%$ & $2,38 \%$ & $2,65 \%$ \\
\hline 80 a 89 & $2,09 \%$ & $2,01 \%$ & $1,87 \%$ & $2,25 \%$ & $2,39 \%$ & $2,25 \%$ & $2,38 \%$ \\
\hline
\end{tabular}




\begin{tabular}{cccccccc}
\hline 90 a 99 & $0,67 \%$ & $0,63 \%$ & $0,52 \%$ & $0,65 \%$ & $0,68 \%$ & $0,68 \%$ & $0,72 \%$ \\
100 y más & $0,04 \%$ & $0,02 \%$ & $0,02 \%$ & $0,03 \%$ & $0,03 \%$ & $0,03 \%$ & $0,05 \%$ \\
\hline SUEG & $2,03 \%$ & $1,93 \%$ & $2,28 \%$ & $2,66 \%$ & $2,85 \%$ & $2,39 \%$ & $2,79 \%$ \\
\hline 60 a 69 & $0,70 \%$ & $0,48 \%$ & $0,73 \%$ & $0,90 \%$ & $1,00 \%$ & $0,69 \%$ & $0,93 \%$ \\
70 a 79 & $0,65 \%$ & $0,62 \%$ & $0,74 \%$ & $0,84 \%$ & $0,95 \%$ & $0,78 \%$ & $0,89 \%$ \\
80 a 89 & $0,51 \%$ & $0,65 \%$ & $0,63 \%$ & $0,73 \%$ & $0,71 \%$ & $0,72 \%$ & $0,74 \%$ \\
90 a 99 & $0,16 \%$ & $0,17 \%$ & $0,17 \%$ & $0,18 \%$ & $0,19 \%$ & $0,20 \%$ & $0,22 \%$ \\
100 y más & $0,01 \%$ & $0,01 \%$ & $0,01 \%$ & $0,01 \%$ & $0,01 \%$ & $0,01 \%$ & $0,01 \%$ \\
\hline
\end{tabular}

Fuente: Elaboración propia con base en el Censo 2018. Nota: JHOG corresponde a Jefe(a) de hogar; PJEF es la pareja del jefe de hogar (cónyuge, compañero(a), esposo(a)); HIJ es hijo(a) o hijastro(a); YER/NUE es yerno o nuera; PAD/MAD es padre o madre y; SUEG es suegro(a).

La segunda posición en el hogar más frecuente entre la población en edades avanzadas la conforman las parejas de los o las jefes de hogar. Por lo general, las mujeres son identificadas dentro de esta categoría, de acuerdo con la división de roles de género en la población de mayor edad, donde los hombres son los jefes del hogar y las mujeres sus parejas. En esta categoría se destaca la frecuencia del grupo de edades entre 60 y 79 años, mientras que en los grupos ulteriores la representatividad va disminuyendo (Tabla 4).

Otro aspecto por resaltar es el alto porcentaje de personas de edad que se encuentra en estado de viudez, que es coherente con la significativa proporción de población en edades avanzadas que son padres, madres, padrastros o madrastras del jefe de hogar. Esto sugiere la existencia de procesos de reagrupación familiar y el paso a hogares multigeneracionales donde son acogidos por sus hijos. Con el fin de complementar los anteriores hallazgos, se realizó un análisis de la actividad económica de la población de 60 años y más en los departamentos con mayores niveles de envejecimiento, según su clasificación en población económicamente activa [PEA] y población económicamente inactiva [PEI]. En la medición del mercado laboral, se define la Población en Edad de Trabajar [PET] está compuesta por todas las personas de 12 años y más en zonas urbanas y las personas de 10 años y más en áreas rurales. La PET se divide en dos categorías: la PEA es la población que trabaja o busca trabajo; y la PEI es aquella población que no lo hacen, por ejemplo los estudiantes, jubilados o amas de casa. 
El Censo de Población de 2018 de Colombia incluye una pregunta sobre la actividad realizada la semana anterior, como periodo de referencia, cuyas opciones de respuesta se pueden clasificar, de manera aproximada, en la PEA y PEI. Esta pregunta sirvió de base para obtener la información de la Tabla 5. En la misma, se puede observar que una mayor proporción de la PEA masculina se encuentra entre 60 y 69 años, un grupo que tiende a mantener un alto grado de independencia, por tanto tienden a permanecer activos laboralmente. A partir de los 70 años, el porcentaje de PEI supera al de la PEA. Se trata precisamente de una edad umbral para el retiro de la vida laboral.

Por otra parte, cabe destacar que el comportamiento de estos indicadores es muy distinto en las mujeres en edades avanzadas. Se puede decir que en la mayoría de grupos etarios la PEI supera a la PEA. La mayoría de las mujeres de edad se dedican a actividades como oficios del hogar y cuidado de otros integrantes del hogar; además, en los grupos de menor edad dentro de la población de edades avanzadas corresponden a la pareja del jefe de hogar, mientras que en edades avanzadas hacen parte de hogares extendidos como las madres del jefe o jefa de hogar. Por tanto, es importante avanzar en la medición de la economía del cuidado, para dimensionar su aporte a la economía de los hogares en Colombia.

En suma, los adultos mayores en los departamentos más envejecidos del país desempeñan roles tradicionales, donde las mujeres desempeñan oficios del hogar y actividades de cuidado, mientras que los hombres trabajan en actividades dentro del mercado laboral en edades a partir de los 60 años y a otras actividades luego de su jubilación. Tal situación hace evidente una clara distinción en el uso del tiempo entre hombres y mujeres de las generaciones más antiguas. 


\section{Tabla 5}

Población Económicamente Activa e Inactiva de 60 y más años, por sexo, en los departamentos más envejecidos de Colombia, según Censo 2018.

\section{Hombres}

\begin{tabular}{|c|c|c|c|c|c|c|c|c|}
\hline & Edad & Antioquia & Boyacá & Caldas & Quindío & Risaralda & Tolima & Valle \\
\hline \multirow[t]{5}{*}{$\overline{\text { PEA }}$} & 60 a 69 & $40,6 \%$ & $37,1 \%$ & $24,4 \%$ & $43,1 \%$ & $42,3 \%$ & $43,8 \%$ & $38,7 \%$ \\
\hline & 70 a 79 & $11,2 \%$ & $12,3 \%$ & $7,6 \%$ & $13,1 \%$ & $12,6 \%$ & $16,3 \%$ & $11,0 \%$ \\
\hline & 80 a 89 & $2,0 \%$ & $2,4 \%$ & $1,4 \%$ & $2,4 \%$ & $2,3 \%$ & $3,3 \%$ & $2,1 \%$ \\
\hline & 90 a 99 & $0,2 \%$ & $0,2 \%$ & $0,1 \%$ & $0,2 \%$ & $0,2 \%$ & $0,2 \%$ & $0,2 \%$ \\
\hline & 100 y más & $0,1 \%$ & $0,1 \%$ & $0,0 \%$ & $0,1 \%$ & $0,2 \%$ & $0,1 \%$ & $0,1 \%$ \\
\hline \multirow[t]{5}{*}{ PEI } & 60 a 69 & $19,9 \%$ & $19,4 \%$ & $35,0 \%$ & $16,0 \%$ & $17,2 \%$ & $13,4 \%$ & $18,9 \%$ \\
\hline & 70 a 79 & $16,9 \%$ & $17,8 \%$ & $21,1 \%$ & $16,1 \%$ & $16,3 \%$ & $14,2 \%$ & $18,5 \%$ \\
\hline & 80 a 89 & $7,6 \%$ & $9,4 \%$ & $8,9 \%$ & $7,7 \%$ & $7,5 \%$ & $7,4 \%$ & $8,9 \%$ \\
\hline & 90 a 99 & $1,4 \%$ & $1,4 \%$ & $1,4 \%$ & $1,2 \%$ & $1,3 \%$ & $1,3 \%$ & $1,5 \%$ \\
\hline & 100 y más & $0,1 \%$ & $0,1 \%$ & $0,1 \%$ & $0,1 \%$ & $0,0 \%$ & $0,1 \%$ & $0,1 \%$ \\
\hline \multicolumn{9}{|c|}{ Mujeres } \\
\hline & Edad & Antioquia & Boyacá & Caldas & Quindío & Risaralda & Tolima & Valle \\
\hline \multirow[t]{5}{*}{ PEA } & 60 a 69 & $9,3 \%$ & $10,3 \%$ & $8,9 \%$ & $11,0 \%$ & $9,2 \%$ & $11,6 \%$ & $12,4 \%$ \\
\hline & 70 a 79 & $1,6 \%$ & $2,4 \%$ & $1,6 \%$ & $2,0 \%$ & $1,7 \%$ & $2,5 \%$ & $2,4 \%$ \\
\hline & 80 a 89 & $0,3 \%$ & $0,5 \%$ & $0,3 \%$ & $0,3 \%$ & $0,3 \%$ & $0,5 \%$ & $0,5 \%$ \\
\hline & 90 a 99 & $0,1 \%$ & $0,1 \%$ & $0,0 \%$ & $0,1 \%$ & $0,1 \%$ & $0,1 \%$ & $0,1 \%$ \\
\hline & 100 y más & $0,0 \%$ & $0,0 \%$ & $0,0 \%$ & $0,0 \%$ & $0,0 \%$ & $0,0 \%$ & $0,0 \%$ \\
\hline \multirow[t]{5}{*}{ PEI } & 60 a 69 & $47,8 \%$ & $42,4 \%$ & $46,9 \%$ & $45,2 \%$ & $47,1 \%$ & $43,0 \%$ & $42,6 \%$ \\
\hline & 70 a 79 & $27,4 \%$ & $28,8 \%$ & $28,3 \%$ & $28,0 \%$ & $28,4 \%$ & $28,3 \%$ & $27,5 \%$ \\
\hline & 80 a 89 & $11,4 \%$ & $13,4 \%$ & $11,9 \%$ & $11,4 \%$ & $11,4 \%$ & $12,1 \%$ & $12,3 \%$ \\
\hline & 90 a 99 & $2,0 \%$ & $2,0 \%$ & $1,9 \%$ & $1,8 \%$ & $1,7 \%$ & $1,9 \%$ & $2,1 \%$ \\
\hline & 100 y más & $0,1 \%$ & $0,1 \%$ & $0,1 \%$ & $0,1 \%$ & $0,1 \%$ & $0,1 \%$ & $0,1 \%$ \\
\hline
\end{tabular}

Fuente: Elaboración propia con base en el Censo 2018. HMB corresponde a los hombres y MUJ a las mujeres. 


\section{Conclusiones}

Los resultados de esta investigación aportan una caracterización de los perfiles demográficos de la población de edad y sus diferencias territoriales en Colombia, tomando como punto de referencia variables como el estado conyugal, la posición en el hogar y la actividad económica. El ciclo de vida de los hogares y de la población de edad determina que permanezcan en hogares nucleares o se agrupen en hogares multigeneracionales donde generalmente no son los jefes, pero continúan realizando aportes a los mismos, producto de sus trabajos o su labor como cuidadores de otros integrantes de los hogares. En este sentido, la participación en la actividad laboral es una opción para las personas de edad de mejores condiciones socioeconómicas, que tienen garantizado un acceso a pensión; pero en las personas de edad que tienden a acumular bajos niveles educativos, escaso acceso a pensiones y baja capacidad de ahorro no constituiría una opción sino más bien una obligación para garantizar ingresos monetarios a sus hogares.

La situación es especialmente compleja en el caso de las mujeres de generaciones más antiguas, que tienden a ser más vulnerables debido a la dependencia económica hacia sus parejas de acuerdo con la división de roles de género que predomina en este tipo de hogares y a su mayor esperanza de vida, lo que se traduce en dificultades de manutención propia en el momento que falte su pareja o dependencia económica trasladada a algún familiar cercano. La mayor parte de este segmento poblacional no cuenta con pensión, pues debido a los roles de género su trabajo ha sido el cuidado del hogar, de sus integrantes y la crianza de sus hijos, todas labores no remuneradas directamente y que tampoco califican a las mujeres de edad como cuidadoras profesionales que podrían ser valoradas en el mercado laboral.

En relación con lo anterior, se destaca que otro de los aportes de esta investigación fue la caracterización del descenso de los indicadores de masculinidad en edades avanzadas en Colombia; lo cual de forma complementaria indica un proceso de feminización de este grupo de edades. Esta tendencia está determinada en buena medida por la evolución demográfica de los departamentos de mayor avance en sus procesos de transición de la estructura por edades, en los cuales la mayor esperanza de vida al nacer de las mujeres se traduce en que su tamaño poblacional exceda al de los hombres en estos grupos de edades. Las mujeres de este segmento etario tienen ocupaciones variadas, que van desde el trabajo formal hasta realizar labores del hogar, de modo 
que, es posible observar dos tendencias divergentes. La primera, la consolidación de hogares extendidos de los cuales hacen parte mujeres de edades avanzadas, con trabajo remunerado o pensionadas, que acogen a otras personas en sus viviendas. La segunda, la conformación de un conglomerado de mujeres de edad avanzada que carecen de empleo formal y se dedican a labores del hogar, de modo que, establecen una relación de dependencia económica con el jefe del mismo.

Por otra parte, se encontró que las diferencias territoriales son más marcadas a escala departamental que al hacer una diferenciación entre la población en áreas urbanas y rurales, donde la desigualdad es menor que la esperada en términos de las estructuras poblacionales por edades, probablemente debido a las características de los patrones de movilidad interna en el país que históricamente han favorecido los intercambios del campo a la ciudad. Las poblaciones de edades avanzadas se ubican en una alta proporción en municipios pequeñas o intermedias con patrones de movilidad periódicos hacia grandes ciudades dependiendo de los servicios que requieran y de las redes familiares que tienen. Por último, es importante resaltar que la transición demográfica ha avanzado a diferentes velocidades a escala regional lo que se ha manifestado en la evolución de estructuras poblacionales disímiles. Sin embargo, precisamente las unidades territoriales más avanzadas en sus procesos transicionales son las que tienen mayor tamaño poblacional en el país, y en las cuales es más evidente el proceso de envejecimiento poblacional.

En este sentido, el sistema de salud público debe prever la carga creciente que se avecina en el mediano plazo por la transición de la estructura por edades del país y consecuentemente desarrollar políticas que apunten a programas e infraestructura apropiados para el cuidado de los mayores, pero más importante a la capacitación e inducción de habilidades que de acuerdo con su edad y condiciones físicas, les permitan su libre desarrollo, esparcimiento, cuidado propio y aporte a la sociedad. 


\section{Referencias}

(1) Alto Comisionado de las Naciones Unidas para los Refugiados, ACNUR. (2010). Recomendación general No. 27 sobre las mujeres de edad y la protección de sus derechos humanos.

Recuperado

de https://www.acnur.org/fileadmin/Documentos/BDL/2012/8335.pdf

(2) Angus, J. \& Reeve, P. (2006). Ageism: A threat to "aging well" in the 21 st century. Journal of Applied Gerontology, 25(2), 137-152. https://doi.org/10.1177/0733464805285745

(3) Ayalon, L. \& Tesch, C. (2018). Contemporary perspectives on ageism. Springer Nature.

(4) Cardona, D. y Peláez, E. (2012). Envejecimiento poblacional en el siglo XXI: oportunidades, retos y preocupaciones. Salud Uninorte, 28(2), 335-348. Recuperado de https://www.redalyc.org/pdf/817/81724957014.pdf

(5) CEPAL. (1999). Encuentro latinoamericano y caribeño sobre las personas de edad. Documentos de seminario técnico-Santiago. Recuperado de http://hdl.handle.net/11362/34670

(6) CEPAL. (2011). Declaración de Brasilia. Segunda Conferencia regional intergubernamental sobre envejecimiento en América Latina y el Caribe: hacia una sociedad para todas las edades y de protección social basada en derechos. Recuperado de https://repositorio.cepal.org/bitstream/handle/11362/21505/1/S2007591_es.pdf

(7) CEPAL. (2013). Consenso de Montevideo sobre población y desarrollo. En Primera reunión de la Conferencia Regional sobre Población y Desarrollo de América Latina y el Caribe (LC/L.3697), Santiago. $\quad$ Recuperado de https://repositorio.cepal.org/bitstream/handle/11362/21835/4/S20131037_es.pdf

(8) Cotlear, D. (2011). Envejecimiento de la población: ¿está preparada América Latina? Washington, D.C.: Banco Mundial. Recuperado de https://openknowledge.worldbank.org/bitstream/handle/10986/2542/588420PUB0Popu11p ublic10BOX353816B0.pdf?sequence $=1 \&$ isAllowed $=\mathrm{y}$

(9) Courtis, C. (2017). Las personas mayores y la Agenda 2030 para el Desarrollo Sostenible: oportunidades y desafios. Recuperado de https://www.cepal.org/es/enfoques/personasmayores-la-agenda-2030-desarrollo-sostenible-oportunidades-desafios 
(10) Dulcey, E. (2010). Psicología social del envejecimiento y perspectiva del transcurso de la vida: consideraciones críticas. Revista colombiana de psicología, 19(2), 207-224. Recuperado de http://www.scielo.org.co/pdf/rcps/v19n2/v19n2a05.pdf

(11) Fajardo, M. \& Rincón, M. (2000). Demografía del envejecimiento y sus implicaciones en sectores claves de la sociedad colombiana. En Wartenberg, L. (comp.). La cátedra abierta en población, 57-94.

(12) Flórez, C. E., Villar, L., Puerta, N. y Berrocal, L. (2015). El proceso de envejecimiento de la población en Colombia: 1985-2050. Recuperado de https://repository.fedesarrollo.org.co/bitstream/handle/11445/1021/Repor_Septiembre_201 5_Fl\%C3\%B3rez_et_al_MCE-C1.pdf?sequence=1\&isAllowed=y

(13) Laslett, P. y Paillat, P. (1999). Cambios de estructura. La emergencia de la Tercera Edad. En Bardet, J.; Dupaquier, J. Historia de las poblaciones de Europa vol. III. Los tiempos inciertos 1914-2000.

(14) Martínez, C. (2013). Descenso de la fecundidad, bono demográfico y crecimiento económico en Colombia 1990-2010. Serie de Estudios a Profundidad basados en las Encuestas Nacionales de Demografía y Salud. Recuperado de https://www.minsalud.gov.co/sites/rid/Lists/BibliotecaDigital/RIDE/INEC/INV/1\%20\%20DESCENSO\%20DE\%20LA\%20FECUNDIDAD\%20\%20BONO\%20DEMOGRAFICO\%20Y\%20CRECIMIENTO\%20ECONOMICO\%20EN \%20COLOMBIA\%201990-2010.pdf

(15) Ministerio de Salud y Protección Social. (2013). Envejecimiento Demográfico. Colombia 1951-2020 Dinámica Demográfica y Estructuras Poblacionales. Recuperado de https://www.minsalud.gov.co/sites/rid/Lists/BibliotecaDigital/RIDE/DE/PS/Envejecimient o-demografico-Colombia-1951-2020.pdf

(16) Montes, V. (1994). Envejecimiento y modernidad. Impactos demográficos. Nueva sociedad, 129, 132-141. Recuperado de https://static.nuso.org/media/articles/downloads/2309_1.pdf

(17) Murphy, M. (2021). Use of counterfactual population projections for assessing the demographic determinants of population ageing. European Journal of Population, 37(1), 211-242. https://doi.org/10.1007/s10680-020-09567-9 
(18) Naciones Unidas. (1982). Plan de Acción Internacional de Viena sobre el Envejecimiento, Asamblea sobre el Envejecimiento, Viena-Austria, julio-agosto. Recuperado de https://www.un.org/esa/socdev/ageing/documents/Resources/VIPEE-English.pdf

(19) Naciones Unidas. (1994). Informe de la Conferencia Internacional sobre la Población y el Desarrollo (El Cairo, Septiembre de 1994) (A/CONF.171/13), Nueva York. Recuperado de https://www.unfpa.org/sites/default/files/pub-pdf/icpd_spa.pdf

(20) Naciones Unidas. (1996). Pacto Internacional de Derechos Civiles y Políticos. Recuperado de https://www.ohchr.org/sp/professionalinterest/pages/ccpr.aspx

(21) Naciones Unidas. (1999). Los Principios de las Naciones Unidas en favor de las personas de edad. Recuperado de https://www.un.org/development/desa/ageing/resources/international-year-of-olderpersons-1999/principles/los-principios-de-las-naciones-unidas-en-favor-de-las-personasde-edad.html

(22) Naciones Unidas. (2003). Declaración Política y Plan de Acción Internacional de Madrid sobre el envejecimiento. Asamblea mundial sobre el envejecimiento de 2002. Viena, Austria. Recuperado de https://social.un.org/ageing-working-group/documents/mipaa-sp.pdf

(23) Nieto, M. y Palacio, L. (2007). ¿Está preparado nuestro país para asumir los retos que plantea el envejecimiento poblacional? Salud uninorte, 23(2), 292-301. Recuperado de https://www.redalyc.org/pdf/817/81723214.pdf

(24) OEA. (2015). Convención Interamericana sobre la protección de los derechos humanos de las personas mayores. Recuperado de http://www.oas.org/es/sla/ddi/docs/tratados_multilaterales_interamericanos_a70_derechos_humanos_personas_mayores.pdf

(25) Pérez, J. (2003). La madurez de masas. Instituto de Migraciones y Servicios Sociales. Recuperado de https://digital.csic.es/bitstream/10261/3110/1/MadurezMasas.pdf

(26) Redondo, N. (2012). Envejecimiento poblacional y condiciones de vida de los adultos mayores: La situación paraguaya en perspectiva latinoamericana. Perspectivas sociales= Social Perspectives, 14(2), 138-161. Recuperado de https://dialnet.unirioja.es/descarga/articulo/4703931.pdf

(27) Robine, J. M. (2011). Age patterns in adult mortality. En Rogers, R. G. \& Crimmins, E. M. (Eds.). International handbook of adult mortality (pp. 207-226). Springer, Dordrecht. 
(28) Rowland, D. T. (2009). Global population aging: History and prospects. En Uhlenberg, P. (Ed.). International handbook of population aging (pp. 37-65). Springer, Dordrecht.

(29) Scherbov, S. \& Sanderson, W. C. (2014). Re-measuring twenty-first century population ageing. En Lutz, W., Butz, W. P., \& Samir, K. C. (Eds.). World population \& human capital in the twenty-first century. Oxford University Press.

(30) Vejarano, F. y Angulo, A. (2015). Vejez y envejecimiento: una mirada demográfica. En Rodríguez, P. y Alvarado, F. V. (Eds.). Envejecer en Colombia. Bogotá: Universidad Externado de Colombia.

(31) Weeks, J. R. (2020). Population: An introduction to concepts and issues. Cengage Learning.

(32) Zavala, M. E. (1996). The Demographic transition in Latin America and Europe. En J. M. Guzmán, S. Singh, G. Rodríguez y E. Pantelides (Eds.). The fertility transition in Latin America (pp. 95-109). Oxford: Clarendon Press.

Cómo citar este artículo: Castellanos, E., Vega, I. y Cristancho C. (2021). Envejecimiento y la transición de la estructura poblacional por edades en Colombia. Tendencias, 23(1), 29-57. https://doi.org/10.22267/rtend.222301.197 